\title{
Posterior Ulnar Vein
}

National Cancer Institute

\section{Source}

National Cancer Institute. Posterior Ulnar Vein. NCI Thesaurus. Code C33387.

A vein that ascends on the posterior surface of the ulnar side of the forearm to drain the palm of the hand. The posterior ulnar vein either unites with the anterior ulnar vein to form the common ulnar vein or with the median basilic vein to form the basilic vein. 